\title{
Parameterization and Evaluation of Seismic Resistance within the Context of Architectural Design
}

\author{
Tomaz Slak $^{1} \&$ Vojko Kilar ${ }^{1}$ \\ ${ }^{1}$ Faculty of Architecture, University of Ljubljana, Slovenia \\ Correspondence: Vojko Kilar, Faculty of Architecture, University of Ljubljana, Zoisova cesta 12, Ljubljana 1000, \\ Slovenia. Tel: 386-1-200-0720. E-mail: vojko.kilar@fa.uni-lj.si
}

\author{
Received: May 8, 2012 Accepted: June 5, 2012 Online Published: June 12, 2012 \\ doi:10.5539/mas.v6n7p17 URL: http://dx.doi.org/10.5539/mas.v6n7p17
}

\begin{abstract}
This paper explores and discusses the possible relations between the architecture and seismic resistance of buildings. The first part of the paper stresses the practical importance of earthquake resistance in every building built in earthquake prone areas. Further on it is shown that the earthquake resistance in architectural expression can be dealt in hidden or concealed principles or on the other hand in revealed or emphasized ways. The paper hypothesize that the architectural design, which to a certain level reflects an earthquake threat, might provide a better designs with stronger architectural identity for buildings in earthquake-prone areas. In this context it summarizes the term "earthquake architecture", which is defined as particular approach to design of buildings in architecture in a way which draws the inspiration from earthquake engineering. Such an approach might be one of the best responses of the architects (in cooperation with structural engineers and earthquake specialists) to the earthquake threats. In the second part of the paper the proposed method for recognition and evaluation of architecture in the context of earthquake resistance is presented. Using this evaluation method, it is possible to classify buildings at several different levels of "earthquake architecture". Case study of three comparable competition projects is presented as example of using this method to evaluate the architectural design in the context of seismic resistance, and at the same time, to indicate the ways in which architecture can play its role part within earthquake resistant design.
\end{abstract}

Keywords: architectural design, built environment, conceptual design, earthquake resistance, earthquake architecture, evaluation, structures

\section{Introduction}

The development of architecture in response to earthquake threats has, over the last few decades, resulted in a special kind of architecture, which is specific for earthquake-prone areas. So-called "earthquake architecture" has in fact arisen as a consequence of "a particular approach to architectural design, which draws its inspiration from earthquake engineering" (Reitherman, 1985; Charleson \& Taylor, 2000; Garcia, 2000; Charleson \& Taylor, 2004; Slak \& Kilar, 2007). The elements or measures required by the relevant technology of this branch of engineering (earthquake engineering) are articulated as special elements of architectural expression (Slak \& Kilar, 2008a). The structural concept should represent the basis of architectural design not just in a visual or symbolic way but mainly in conceptual sense.

In our previous researches it has been established that "earthquake architecture represents a link between earthquake engineering and architecture, and eliminates the problems related to the lack of knowledge and the inability to develop special and, within the framework of earthquake-resistant construction, original architecture" (Slak \& Kilar, 2008b). This paper presents in last few years developed and tested method for the evaluation of architecture within the context of earthquake resistance, which can be used for practical, educational and research purposes. In addition to that it is also useful for comparative studies of different buildings, or as an aid for the assessment of the results of architectural competitions.

Nowadays, due to demanding legislation, standards, safety reasons, etc., the construction of buildings, in earthquake-prone regions, without a suitable earthquake-resistant structure is inconceivable. However, it is possible to design buildings in such a way that their seismic resistance is not readily expressed, and the influence of the load-bearing structure on the architecture is minimal. The earthquake resistance of a building may be concealed, but in this case it is separated from the architecture. Alternatively, the actual architecture of a building 
can respond within its own concept, with the architecturally-articulated increased horizontal stiffness of the building or, symbolically, with metaphorical changes in the design. Earthquake architecture combines the best of both fields and establishes a new type of approach to construction in earthquake-prone areas, which is mainly in compliance with the measures of architectural excellence. The complex requirements of earthquake engineering have a direct influence on the design of the structure, and thus also on the architectural design and concepts, so a detailed examination of these effects should be the basis for architectural work in earthquake-prone areas (Mezzi, Parducci, \& Verducci, 2004).

With the introduction of ever more detailed standards and regulations, the principles of earthquake-resistant design have become important determining factors in the architecture of earthquake-prone areas (Taranath, 2011). It seems reasonable to suppose that architecture should always be local, i.e. designed in accordance with the micro-location features of a particular area, and that it should in some way respond to the earthquake threat. It is believed that, in the present concern for sustainable and regional development, and in the search for a new kind of expression in architecture, the latter's "response to earthquake threats could present an important source of stronger architectural identity, typical of earthquake-prone regions" (Slak \& Kilar, 2007). Adjustment to the requirements of earthquake-resistant design is sometimes regarded as a limitation of artistic freedom $(\mathrm{Xu}$, Xing, \& Guan, 2012), also in trends coming from those parts of the developed world which are not prone to earthquakes (e.g. the Netherlands, Great Britain, and Scandinavia). However, the essence of this problem is not in its limitations, but rather in a lack of knowledge and the inability to develop a particular and, within the framework of earthquake-resistant construction, an inventive type of architecture (Slak \& Kilar, 2008b). Earthquake architecture is thus one of the possibilities for increasing the architectural identity of earthquake-prone areas, since it presents a well-argued approach for the shaping of architecture in such areas.

\section{Architecture within the Context of Earthquake Resistance (Earthquake Architecture)}

The phrase "earthquake architecture" was first introduced in the paper "Earthquake Engineering and Earthquake Architecture" by Bob K. Reithermann in 1985. He noted that "whereas 'earthquake engineering' was a common term at organizations and conferences, 'earthquake architecture' had an unaccustomed ring to it", and asked "Is there such a thing as earthquake architecture, and if so, what is it". Christopher Arnold uses this phrase to describe a degree of the architectural expression of some aspect of earthquake action or resistance (Arnold, 1996; 2001). And as we already established before (Slak \& Kilar, 2008a), "the breadth of expressive possibilities ranges from metaphorical (only visually expressed) to the more straightforward exposure of the seismic technology used".

The Nunotani Office Building in Tokyo (Figure 1) is an extreme example of metaphor and symbolism used in an architectural response to seismic design. "Its disjointed and displaced facade elements are intended to represent a metaphor for the waves of movement as earthquakes periodically compress and expand the plate structure of the region" (Ciorra, 1995; Fernandez-Galiano, 2000). This building does not actually represent the symbolism of earthquake architecture, but rather the symbolism of an earthquake threat. Pointing out instead of solving the problem in metaphor is actually a philosophical discussion (Medway \& Clark, 2003). However, the fact remains that "seismic issues have generated an innovative architectural design concept" (Charleson \& Taylor, 2000).
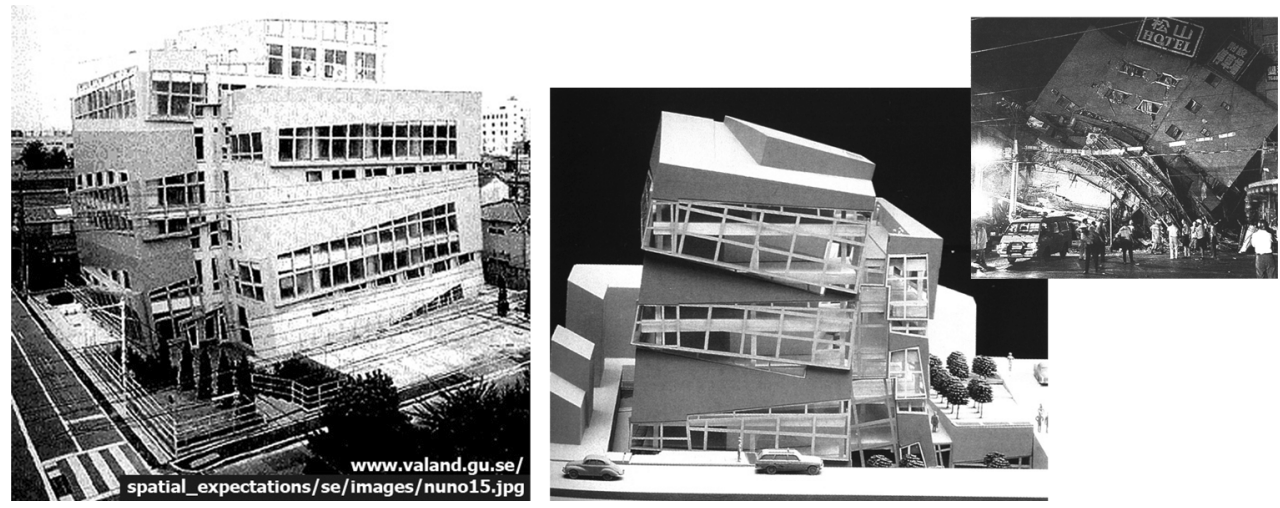

Figure 1. An example of symbolism and metaphor by means of which architecture is able to react to earthquake threats: The Nunotani Office Building, Tokyo, Peter Eisenman, 1998 (source: Ciorra, 1995; Fernandez-Galiano, 2000) 
Earthquake architecture can be defined as any visual or conceptual inter-connection between the concepts of earthquake engineering and those of architecture. Thus "the inclusion of the requirements of earthquake-resistant design in the process of the creating and conceptualizing of the architecture of a real building can be based on the visual or the conceptual level" (Slak \& Kilar, 2008a). Visually, one can, on the one hand, discuss hidden and concealed ways of expressing earthquake-resistant architecture, and, on the other hand, revealed or emphasized ways (Figure 2).

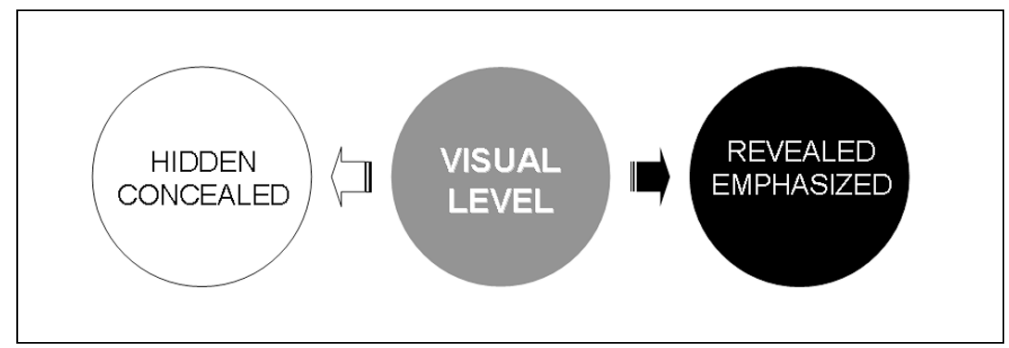

Figure 2. Visual perception of earthquake architecture

From the conceptual point of view (Figure 3), earthquake architecture is realized only by including the principles of earthquake engineering within the architectural concept itself, thus achieving the highest level of cooperation through identification, where architecture is based entirely on the principles of earthquake engineering. This should not be understood as an engineering approach, but rather as an architectural articulation of a building's structural basis. Architects should avoid building architecture innovation that just "pays attention to appearance, with the structure form against the law of building science" (Xu, Xing, \& Guan, 2012). Strategies for the realization of the vision of a more widely accepted earthquake architectural approach inevitably depend on architects. Structural engineers need to be the catalysts for this vision to be caught and developed.

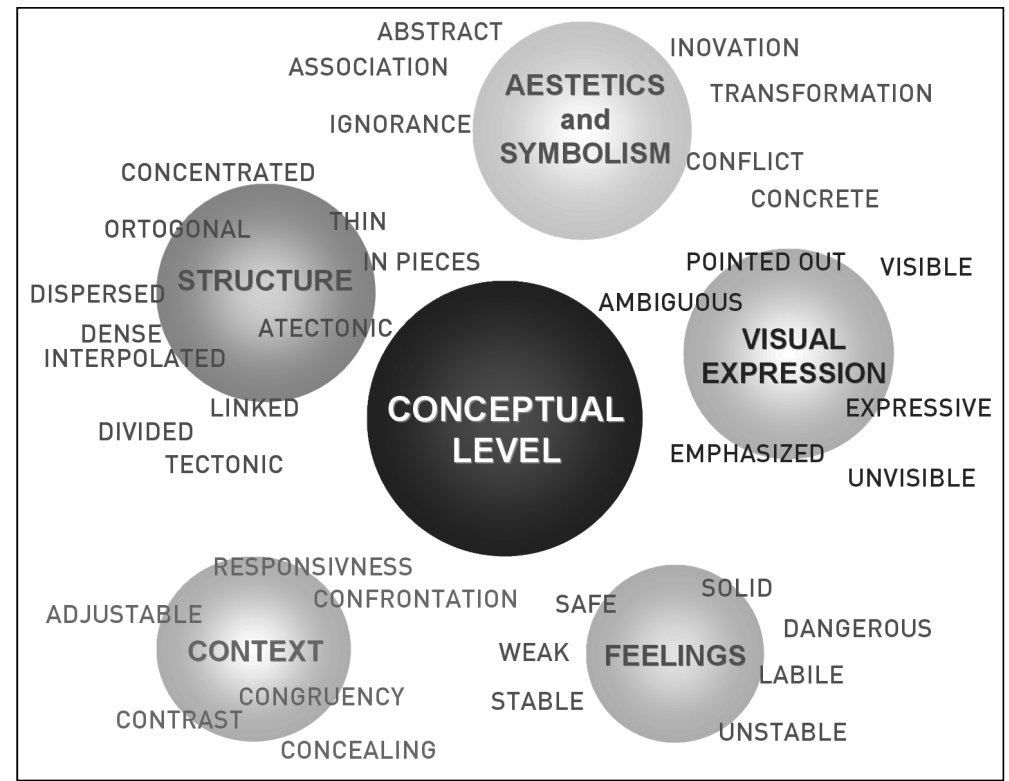

Figure 3. Conceptual perception of earthquake architecture, where visual expression is just one of a considerable number of relevant characteristics

Earthquake architecture represents a special approach to architectural design, in which the main source of inspiration comes from earthquake engineering, and where the specific local tectonic activity becomes a generator for the architectural design. Earthquake architecture is any response of the architect to the earthquake threat through creative architectural transformation. It embraces the visual effects of seismic design on architecture, the application of earthquake engineering technology, which helps to enrich the aesthetic expression of a building, as well as the decision to use the principles of seismic design as the main architectural motif. 
Identification and evaluation of architecture within the context of earthquake resistance is the first step towards earthquake architecture, which is one of the best argued ways for the design of architecture, typical for earthquake-prone areas. It can be concluded that the basis of earthquake architecture lies in contextualism and critical regionalism, as has been described by K. Frampton, whereas the architectural product in general arises from the natural laws embraced in tectonics, and is a consequence of artistic intention, which exceeds bare technical skills and reaches beyond functionality (Frampton, 1982).

\subsection{Identification and Evaluation of Architecture within the Context of Seismic Resistance}

The initial concept of proposed method was first time introduced as a test proposal on $14^{\text {th }}$ World Conference on Earthquake Engineering (Slak \& Kilar, 2008a). Throughout few years it was improved and tested on theoretical and practical case studies. The proposed method for the evaluation of architecture within the context of seismic resistance or, in brief, earthquake architecture, originates from the above description of earthquake architecture itself. It combines together an earthquake-engineering (structural) part and an architectural (symbolic) part, which together form two basic groups of evaluation parameters, as follows:

1) The parameters which are connected to the earthquake resistance of a building.

2) The parameters which are connected to the architectural response to earthquake threats.

Both sets of parameters require evaluation of the building data which can be obtained from detailed drawings of the architecture and structure, as well as from the general concept, context, and installation at a particular location, and the overall appearance of a building, including not only its visible but also its conceptual and concealed characteristics.

Some parameters for the evaluation of any kind of architecture tend to be more objective than others, which are of a more subjective nature. The most sensitive parameters appear to relate to be the evaluation of the architectural-symbolic segment, which usually depends on the evaluator's personal point of view. If a reliable result is to be obtained, the evaluator must have some knowledge and experience of earthquake architecture, as well as of structural engineering, and it is advisable that each group of parameters is evaluated by a different expert. In the described study the proposed individual criteria were chosen in such a way that it is possible to achieve adequate objectivity in a two-step evaluation process. In the first step, each earthquake-engineering or architectural parameter is classified as poor, adequate or excellent. In the second step, the evaluation is corrected with "-" and "+" intermediate values, resulting in a final scale from 1 to 7 , as shown in the case study (see Figures 22-24) and in Figures 15 and 25.

Some parameters are more significant than others, and represent the core of the evaluation. This is why it is recommended that the importance of each of the parameters be defined in advance by a higher evaluating committee. In order to achieve higher objectivity it is proposed that so-called external parameters, with different influence on the importance of parameters, be included.

\subsection{The Architectural Parameters}

The parameters which would adequately present an architect's architectural-symbolic response to an earthquake threat cannot be entirely defined as objective measures, independent of the evaluator. Based on the different criteria that can be found in the literature (e.g. Saunders, 1999; Giedion, 1997; Alexander, 2002; Forster, 1999; Frampton, 1985; Slak \& Kilar, 2008a; etc.), we have proposed eight evaluation parameters which are related to the architectural and symbolic response of a designer to an earthquake threat. We have combined them in three main groups. The first group represents general architectural criteria for evaluating architecture:

A1) Artistic impression and the harmony of the architectural solution. General architectural value with regard to the wider space and the author's criterion. Estimation of exceptionality of the architectural product with regard to its spatial context, the project task, and the architect's concept. Artistic (architectural) expressiveness and consistency of the chosen concept (e.g. in its composition, structure, material, details, texture, and colours).

A2) Context as a special point for evaluating the architectural response to the conditions of space and the environment (which includes seismic activity). Estimation of environmental influences on building design and response to the initial conditions, which is derived from the context of the site.

A3) Architectural innovation, originality and harmony within the time of creation. This criterion embraces the contemporaneity, progressiveness and avant-gardeness of architecture, which is a so-called developmental measure. It evaluates the architectural and artistic value with regard to the time of its creation, as well as the use of the most up-to-date materials and principles in architectural design. Architecture as a manifest and philosophical viewpoint - as a movement of frontiers. 
The second group of parameters is more focused on earthquake and structural factors, and on the logic of tectonics:

A4) Achievement of symbolic value, which is derived from the earthquake threat (symbolic/metaphoric response in general). Also the level of metaphoric response to earthquakes, and, in this connection, estimation of the elevation of the structural rules of seismic design to the level of an architectural symbol (Figure 4).
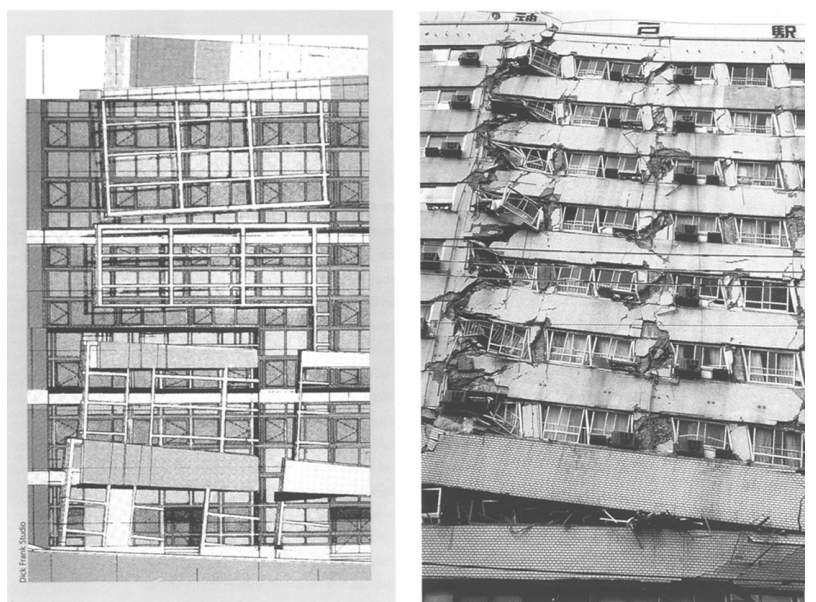

Figure 4. An example of a symbolic/metaphoric response to earthquakes: the Hotel Atocha, Madrid, Peter Eisenman, 1990 (left), and damage after the Kobe earthquake in 1995 (source: Fernandez-Galiano, 2000)

A5) Building morphology and tectonics in the architecture of a building, with emphasis on the seismic design of the whole and of the individual parts (Figure 5). Evaluating tectonics within the context of earthquake resistance (composition, shape, geometry, proportions, etc.).

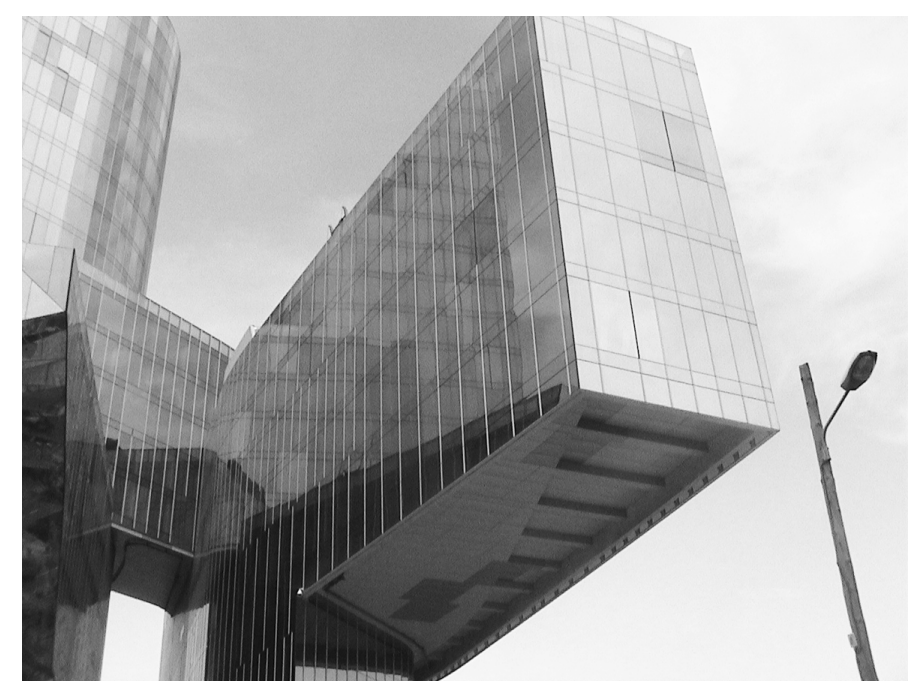

Figure 5. An example of extreme tectonic architecture: the Natural Gas Tower Building, Barcelona, Enric Miralles, EMBT Architects, 2007 (photo: V. Kilar)

A6) Interaction between architecture and the earthquake threat. Evaluation of the connection between the main architectural concept with the principles of earthquake-resistant construction in order to produce a harmonious whole (Figure 6). 


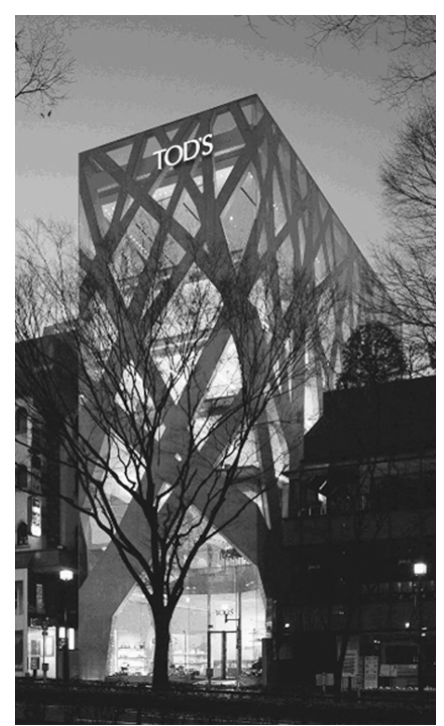

Figure 6. An example of an architectural concept which is well-connected to the principles of earthquake resistant design: Tod's Omotesando Building, Tokyo, Toyo Ito, 2004 (source: El Croquis, no. 123, 2005)

In the last group there are two parameters which can be used to evaluate the architectural product on the concrete, technical (technological) and functionality level:

A7) Functionality, the rational use of space and the quality of living in general, also in connection with earthquake-resistant design. The influence of seismic design on functionality, and vice versa. The success which can be achieved in the harmonization of seismic design and functionality of the building, in the sense of minimizing the impact of usability to the structural minimum.

A8) Expression of seismic resistance in the appearance of a building, on the inside, through details, and in the earthquake technology used. The level of incorporation of an earthquake resistant structural system into the appearance of a building at every level of visual perception (Figures 7-10).

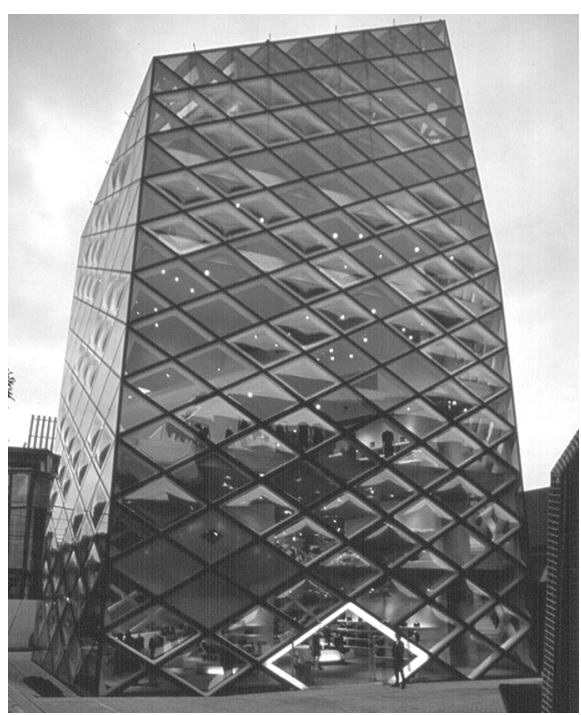

Figure 7. An expression of lateral force-resisting systems clearly confirms the provision of seismic resistance by means of exposed bracing. Prada Aoyama Boutique, Tokio, Herzog \& de Meuron, 2003 (source: El Croquis, no. 129/130, 2005) 


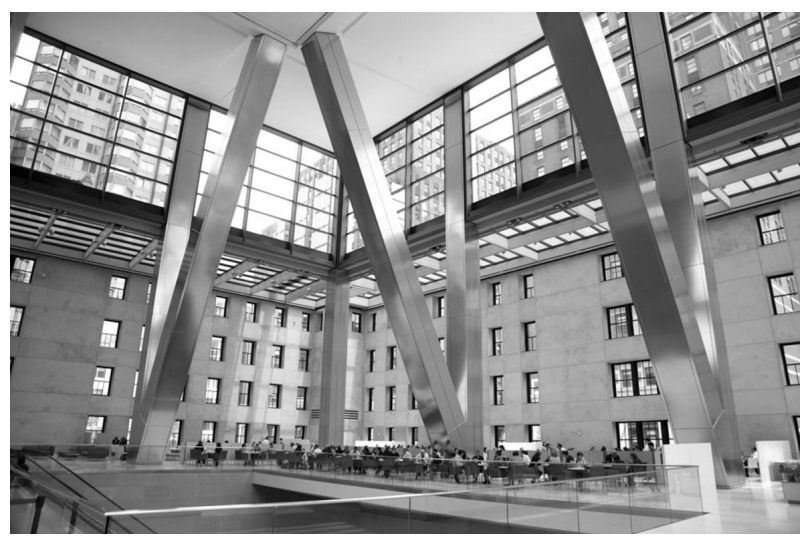

Figure 8. An expression of lateral force-resisting systems in a building interior: the Hearst Tower, New York, Foster \& Partners, 2006 (source: http://www.worldarchitecturenews.com/)

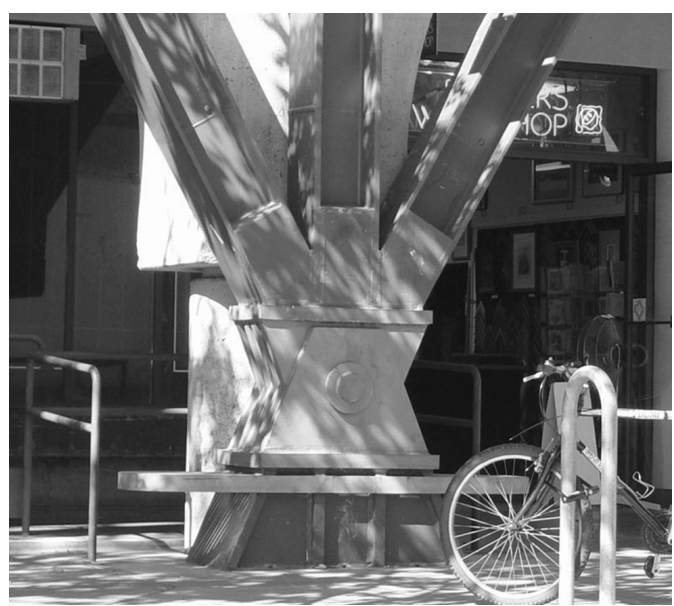

Figure 9. An expression of building foundation details: the exterior shear-resisting truss of a retrofitted building, 2000 (source: http://en.wikipedia.org/wiki/File:ExtReenfDetail.jpg )

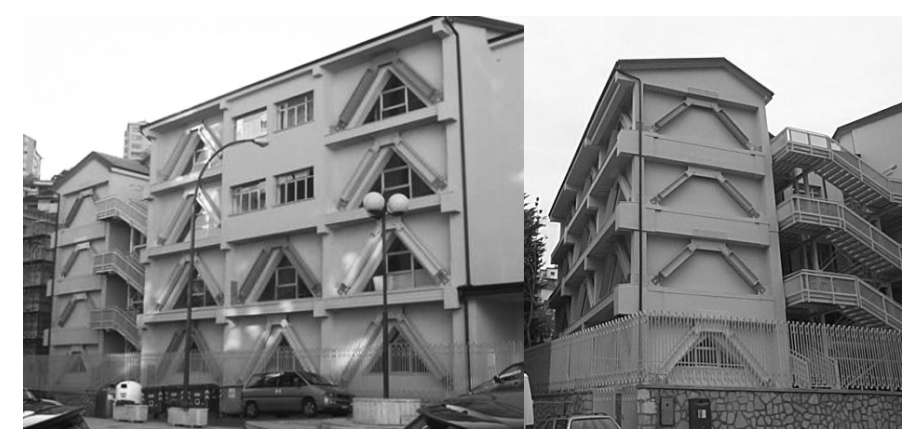

Figure 10. Exposure of a modern technological system used for a retrofitted building: the "Domiziano Viola" school at Potenza, and its visible energy-dissipating braces provided with elastic-plastic dampers, completed 2002 (source: http://earthquakesafe.blogspot.com/ and http://www.iitk.ac.in/nicee/wcee/article/14_S05-02-018.PDF)

A scheme of the architectural parameters which are involved in the evaluation of architecture within the context of earthquake resistance, as well as their interconnectedness, is shown in Figure 11. 


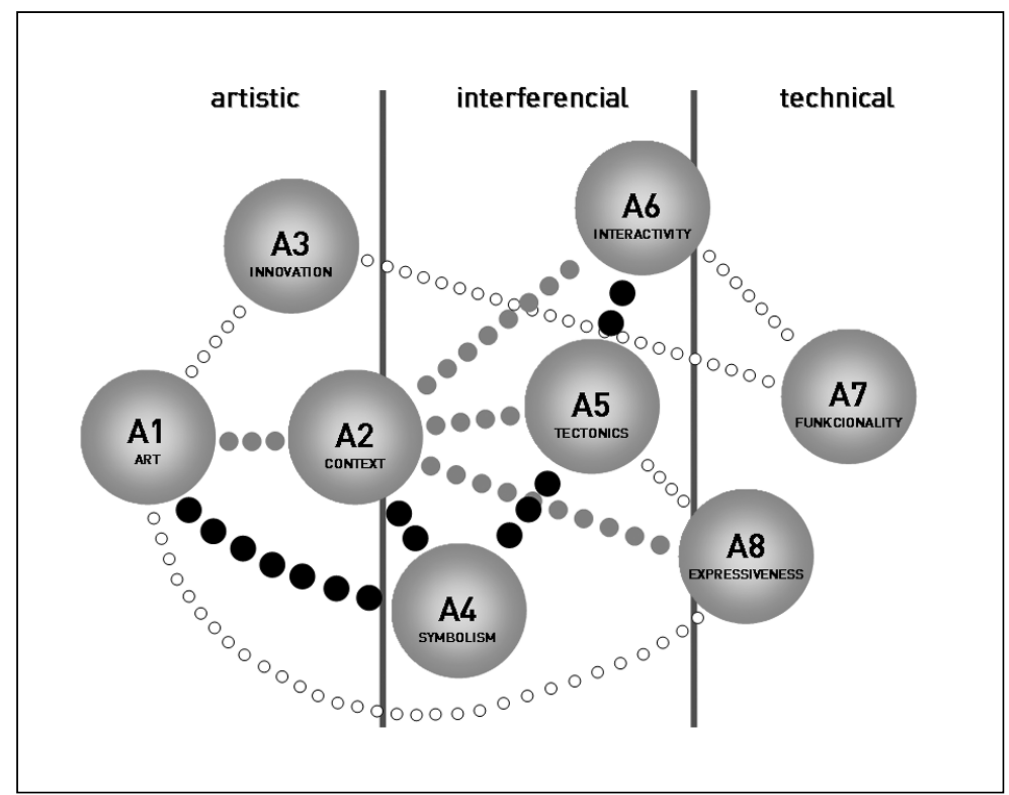

Figure 11. Scheme of the architectural parameters, their classification and interconnectedness

\subsection{The Structural Parameters}

The field of earthquake engineering field is not, in general, favourably inclined to simplified integral criteria which might provide reliable information about the earthquake resistance of any building without the performance of detailed analyses and studies. However, in the case of the seismic evaluation of existing buildings, the profession has developed some guidelines which might be used to identify the seismically most vulnerable buildings and the associated earthquake-related risk, so that such buildings could be further analyzed and retrofitted. The criteria which have been developed for the evaluation of the integrity of existing structural systems and their resistance to horizontal loads can be found in the literature, together with different sets of evaluation parameters (FEMA reports No. 178 and No. 454; Tomazevic, 1996; 2001; Kilar, 2000; 2004). However, for the purpose of the research which is described in this paper, some of the most important parameters have been selected and adapted for the evaluation of new as well as existing buildings. The following eight structural evaluation parameters were taken into account:

S1) General quality, suitability and reliability of the proposed (or built) building system to resist earthquake loading, and the capability of the vertical elements to transfer earthquake loads onto the foundations. Evaluations are based on the verification of general building structure parameters (e.g. load paths, maximum spans, the distribution of the load-bearing elements, the positions of centres of masses, stiffness and strength, the height-to-length ratios of shear walls and openings, the frame's column-beam proportion ratios, the deficiencies in various elements, weak links, etc.) and the basic design checks or results of preliminary analyses (e.g. evaluation of the shear stresses in walls, checking of inter-storey drifts, overturning safety etc.).

S2) Configuration of the building system and regularity in plan and elevation. Special problems considering configuration issues like: the presence of weak or soft storeys, geometrical irregularities, setbacks, mass irregularities, vertical discontinuities, and torsion are evaluated. Control of load paths in this criterion is particularly important.

S3) The predominant material of the structural system with regard to the configuration of the building structure and taking into account the selected structural system.

S4) Foundations and their ability to transfer the loads onto the ground (e.g. dimensions, foundation performance, possible liquefaction, and slope failure).

S5) Inter-storey diaphragms and their ability to transfer the horizontal loads onto the vertical load-resisting elements (e.g. proportions, plan irregularities, continuity, diaphragm openings immediately adjacent to shear walls). 
S6) Quality of the structural details in relation to the requirements of the relevant earthquake codes (e.g. higher considered ductility class DCH/DCM, quality of the connection details, reinforcement details of the load-bearing elements, wall anchorages, inter-storey and roof connections, anchorage of girders and beams).

S7) Non-structural elements and their influence on the main structural system (e.g. the appropriateness of the connections of infill walls and non-structural elements of greater mass to the main load-bearing elements).

S8) Use of contemporary technological systems and their ability to reduce earthquake loads.

The proposed seismic/structural evaluation could be supported by the results of static analyses and comparison studies. A reliable evaluation of these criteria requires a certain amount of structural engineering expertise, and should therefore be performed by a structural engineer or other expert.

Figure 12 shows the scheme of structural parameters for the evaluation of architecture within the context of earthquake resistance, and the possible influence of the architect on them.

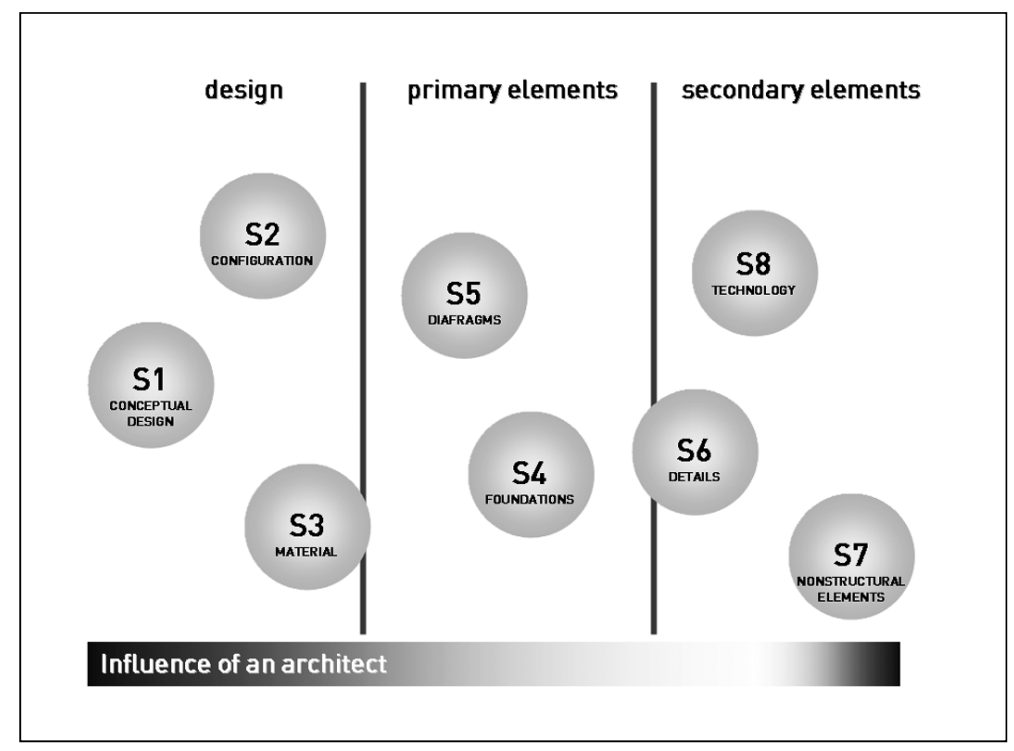

Figure 12. Scheme of the structural parameters, their classification and the effect of architect's design on them

\subsection{The External Parameters}

Beside these two main, above-described groups of parameters, there are some external parameters which are not the consequence of decisions made by a design engineer. These external factors represent the conditions at a site, or some minimum standards that have to be considered. It was decided to emphasize three main external parameters (E1-E3) and a special fourth parameter (E4), which takes into account the field of economics:

E1) The level of earthquake threat (i.e. the seismic activity at a particular site), which is determined from seismic maps and on the basis of the geological factors relevant to the location.

E2) The importance of the building (according to the obligatory standard, i.e. EC8) and its historical or cultural significance.

E3) The used standards and the possibility of the inclusion of state-of-the-art knowledge in the building's design. This parameter includes the year of construction (as related to the standards), and the latest achievements in the fields of structural and earthquake engineering, as well as in architecture.

From the economic point of view there must be some kind of balance between funds invested for the achievement of earthquake resistance, and the potential costs for the repairing of an earthquake-damaged building, as well as for the interruption of manufacturing processes, or for loss of life and injuries. It also describes the ratio between the minimum investment needed according to the obligatory standards and the costs of the built or planned structure.

E4) The economic legitimacy of the costs of the structure and of all the included systems for earthquake-resistant design, and the legitimacy of the architectural solutions, i.e. the rationality of the chosen materials, the structural system, and the actual execution details (Figure 13). 


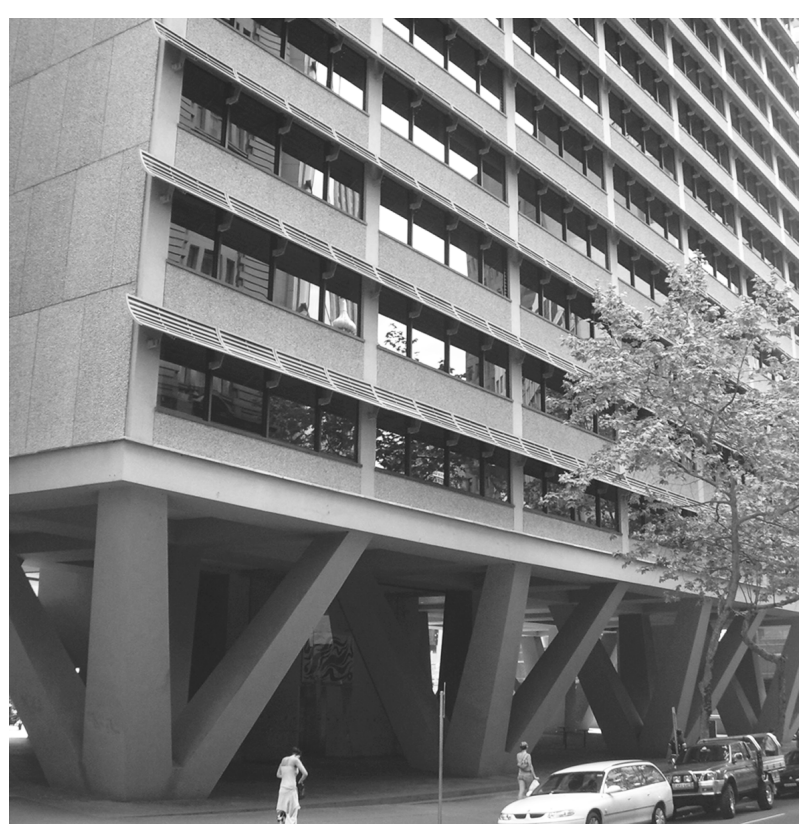

Figure 13. An economically questionable structural system used in the case of an office building in Sydney, built at the end of the 1990's (photo: V. Kilar)

\section{Evaluation System: The Weighting of Basic Parameters and the Influence of External Parameters}

At the first step of the evaluation, the evaluator or expert grades each of the above mentioned architectural or structural parameters in order to obtain the architectural and structural grades $G_{A i}$ and $G_{S i}$, respectively, for each $i$-th examined parameter ( $i=1$ to 8 in our evaluation proposal). Since some of the parameters may be of different importance, a higher instance (authority) at the second level of evaluation might define the importance and influence of each parameter in the general evaluation by the use of additional modification factors $\gamma_{A i}$ and $\gamma_{S i}$. This changes the influence of different parameters in the final grade for each half of the evaluation (i.e. the architectural and structural part).

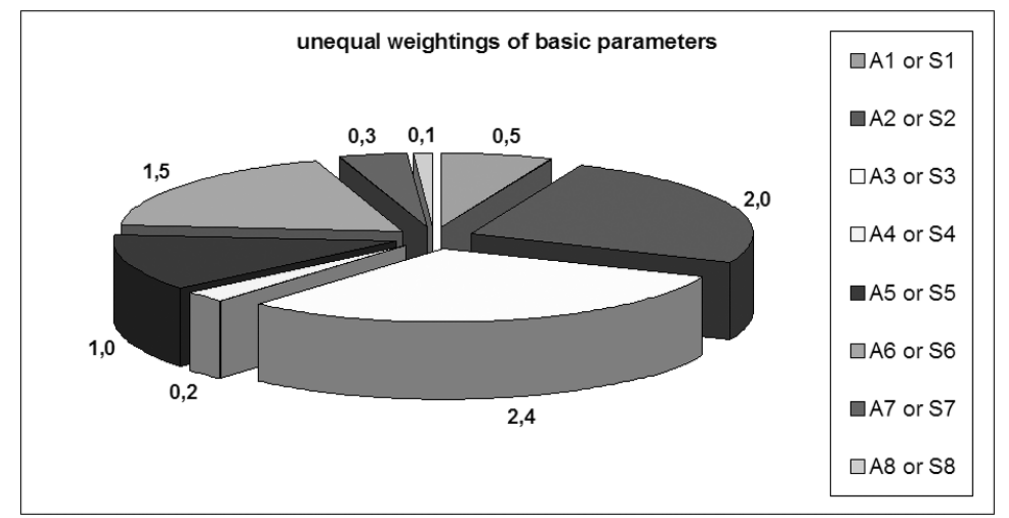

Figure 14. Example of the unequal weightings of the basic parameters, defined by a higher level of evaluation

The next step is to consider the influence of the external parameters $E_{i, j} \quad(j=1$ to 4 in our evaluation proposal) to the observed architectural or structural parameter $A_{i}$ or $S_{i}$. In order to define the influence of external parameters, the average of these four external parameters $\left(\overline{E_{i}}\right)$ is calculated for each basic parameter. The modification factors $\left(\gamma_{\mathrm{Ai}}\right.$ and $\left.\gamma_{\mathrm{Si}}\right)$ are multiplied with the average external parameters to obtain the evaluation grade ponders $\left(\Gamma_{A i}\right.$ and $\left.\Gamma_{S i}\right)$.

$$
\Gamma_{A i}=\overline{E_{i}} \cdot \gamma_{A i}
$$




$$
\Gamma_{S i}=\overline{E_{i}} \cdot \gamma_{S i}
$$

The final pondered grade of each parameter $\left(\mathrm{G}_{\mathrm{Ai}-\mathrm{P}}\right.$ and $\left.\mathrm{G}_{\mathrm{Si}-\mathrm{P}}\right)$ is than calculated as:

$$
\begin{gathered}
G_{A i-P}=\frac{\Gamma_{A i}}{\overline{\Gamma_{A i}}} \cdot G_{A i} \\
G_{S i-P}=\frac{\Gamma_{S i}}{\overline{\Gamma_{S i}}} \cdot G_{S i}
\end{gathered}
$$

where $\overline{\Gamma_{A i}}$ and $\overline{\Gamma_{S i}}$ represent the average of architectural and structural grade ponders, respectively.

The above-explained evaluation method can be best understood from interactive tables presented in case study (Figures 22-24). In the case when all the ponders and influences of the external parameters are set to 1.0, the total grade is a simple average of the grades for the individual parameters.

\subsection{Presentation in the Form of a Radial Diagram}

Figure 15 shows the results obtained in the case of the use of the proposed method for an imaginary building with all recorded grades, ponders and averages. The results are presented in the form of a radial diagram for the structural parameters (shown on the left hand side) and the architectural parameters (shown on the right hand side), and their average values (indicated by a dashed line). The architectural average defines the architect's symbolical, visual and conceptual responsiveness to the earthquake threat. The earthquake engineering average shows the quality of earthquake resistant design solution and the level of seismic resistance of the building. More concrete examples of this evaluation process are given in the case study, which is provided at the end of the paper.

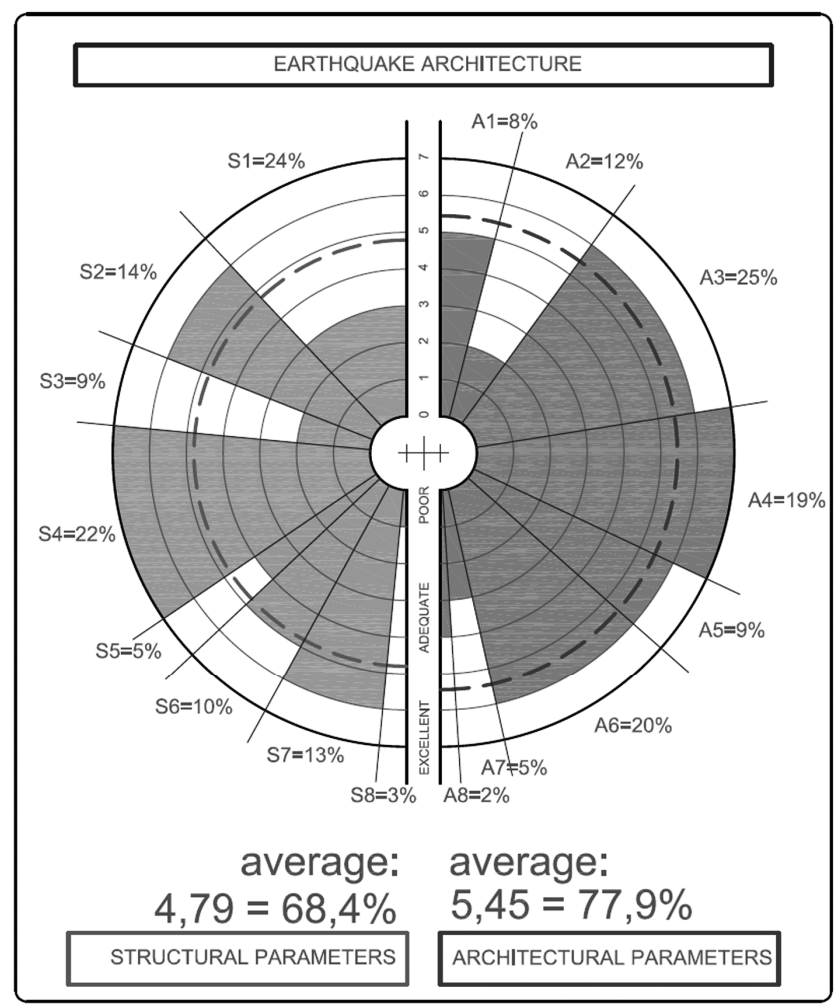

Figure 15. Results of an evaluation in graphic radial form obtained by the proposed method for an imaginary building. The highly-rated parameter S4, for example, raises the average of the structural part of the evaluation because of its high weighting 
This method could be applied (just by the corresponding replacement of the parameters) to the evaluation of different types of human activity which combine together artistic (creative) qualities and technical-engineering qualities. There are many such combinations in the field of architecture (Figure 16).

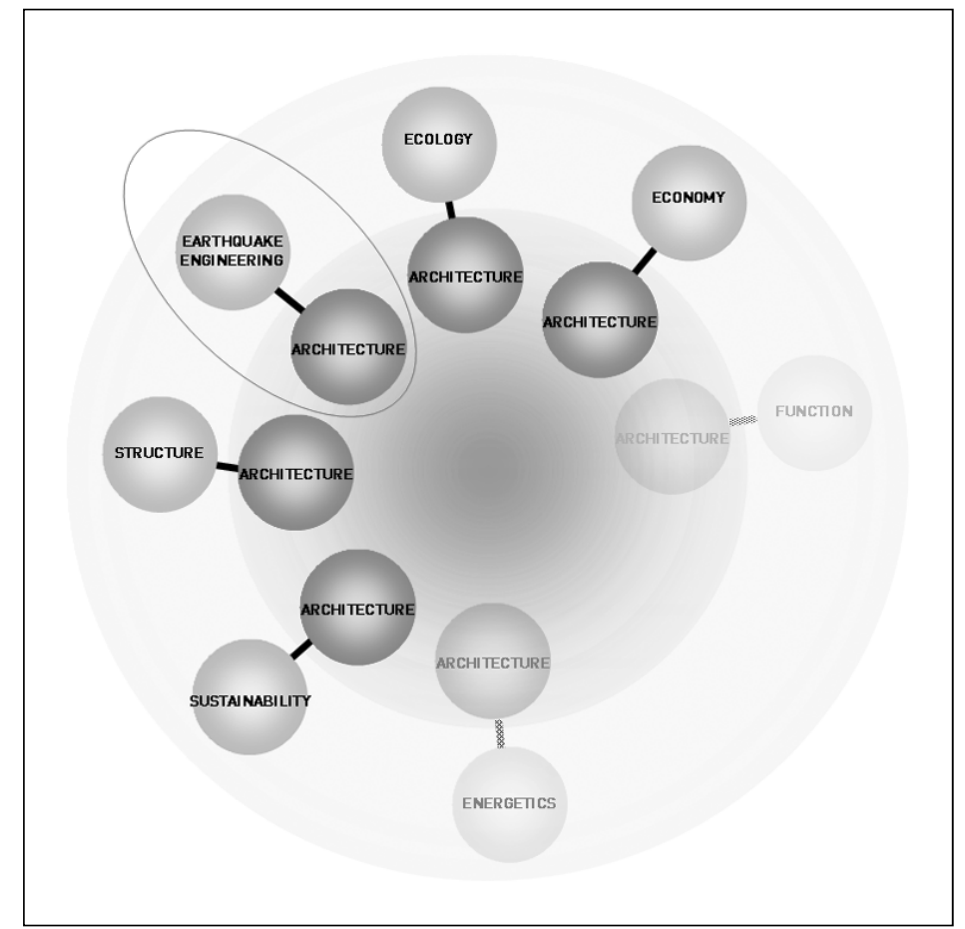

Figure 16. The proposed method can be applied to different pairs of architectural qualities, simply by changing the other half of the parameters

When performing evaluations, it is very important not to merge the results of each half (i.e. the architectural response and the earthquake-engineering measures) of the evaluation. It is believed that there might be examples where the total grade as an overall average could be misleading. For example, if just one half of the parameters reach the highest score (e.g. only the architectural half or only the structural half), it is clear that, in spite of this, the building might not fulfil the criterion of architecture which is an adequate response to the expected earthquake threat. Poor architectural response should not be "hidden" in the average of the overall evaluation because of its structural adequacy, and vice versa: only the architect's symbolic response, without adequate and concrete earthquake resistance, might result in an undeserved high score/average.

\section{Discussion}

The proposed method can be used to classify architecture within the context of earthquake resistance, at different levels of response intensity. With the definition of levels it is possible to describe structural adequacy, as well as tectonic and architectural response to earthquake treat. Since the evaluation method can provide very accurate results it is, for the purpose of broader objective evaluation, advisable to form several different levels of architectural response to earthquakes. We have proposed the classification into four basic levels (see also Slak \& Kilar, 2008a). Starting at the lowest (zero) level, which represents "anti- or non-earthquake" architecture, this is followed by three increasing intensity levels (Figure 17): 


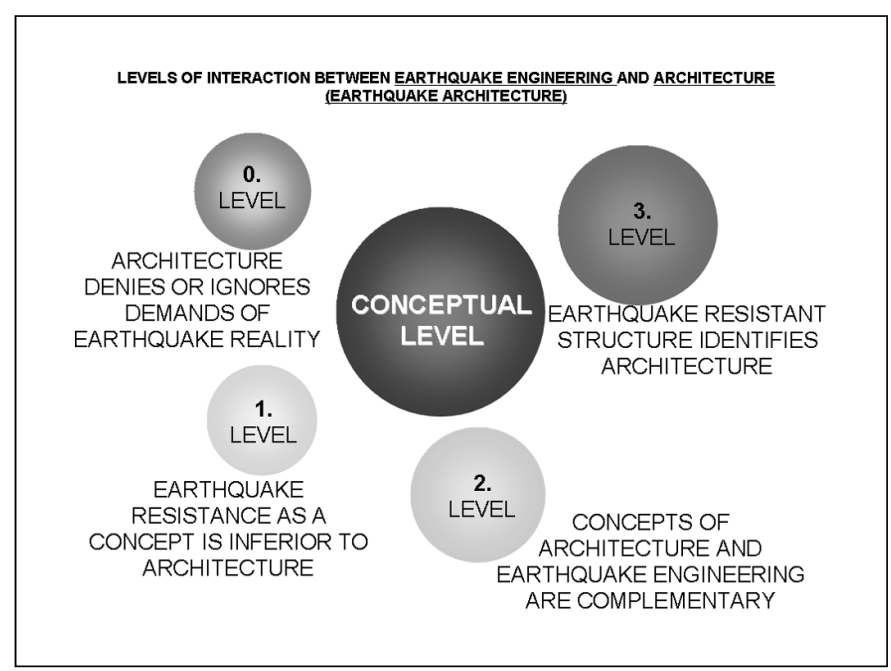

Figure 17. The conceptual approach to earthquake architecture, with the proposed four levels of architectural and structural response to earthquakes

In (Slak \& Kilar, 2008a) the authors have already proposed four levels of earthquake architecture:

- Level 0: Non-earthquake architecture which in the evaluation method reaches a maximum score of $25 \%$.

- Level 1: Inferior earthquake architecture which in the evaluation method reaches scores of between $25 \%$ and $50 \%$.

- Level 2: Balanced earthquake architecture which in the evaluation method reaches a score equal to between $50 \%$ and $75 \%$.

- Level 3: Thorough earthquake architecture which can reach the highest possible scores in the evaluation method (75-100\%).

The suggested divisions between levels are not mathematically clear and the transitions from one level to another are sometimes possible in the process of architectural design. It should be pointed out that some architectural design effect can reduce the horizontal resistance of a building and as such cannot reach higher levels of earthquake architecture. In some cases, due to the desire to "provoke", an architectural solution may even cause weaknesses or conscious structural mistakes. In this case, a negative version of the relationship within earthquake architecture could be imagined.

It has been noted that "there is not much earthquake architecture in earthquake-prone areas. It can be claimed that a large number of buildings do not show architectural, i.e. visible or conceptual characteristics of earthquake architecture, or they merely use hidden methods of earthquake-safe construction and earthquake engineering technology" (Slak \& Kilar, 2008b). In these cases the possibility of using earthquake architecture as a form of expression remains unrealized. Architecture should respond to the conditions of the site, so that architecture within the context of earthquake resistance is a legitimate and argued choice for the design of buildings in earthquake-prone areas.

\section{Case Study of the Evaluation of Three Competition Solutions for a 6-storey Commercial Building in Ljubljana - Summary}

The three prize-winning architectural solutions from an international competition for the design of a six-storey commercial building in Ljubljana (Slovenia) are suitable for a demonstration of the evaluation method in practice. All three buildings are comparable, placed in the same context and have the same origins in the basic design layout. This is why the effects of the external parameters and the importance of the basic parameters are the same for all three of them.

In the given case it must be considered that in the competition plans just the conceptual design is given. Some of the parameters for the evaluation could not be evaluated at this stage. In the conceptual outline the purpose of the evaluation is, above all, to ensure the provision of an adequate earthquake-resistant concept, to warn about inadequacies, and to direct planners towards earthquake architecture. 


\subsection{The Commercial Building Structure - Competition Outlines}

The building includes a commercial ground floor of above-average height, a mixed business-commercial mezzanine, and above these four business floors in the shape of small towers. In the underground storeys there are three garage and/or service floors. Important parameters to be considered in design were also the building size (the whole building is nearly $200 \mathrm{~m}$ long and requires structural dilatations), the required logical tectonic load paths of the small towers, and the structural connections between them, as well as the configuration of the lower business-commercial part of the building. All three of the competition entries are shown as conceptual models in Figure 18. The most noticeable highlights of the described structural and architectural evaluations are discussed below.

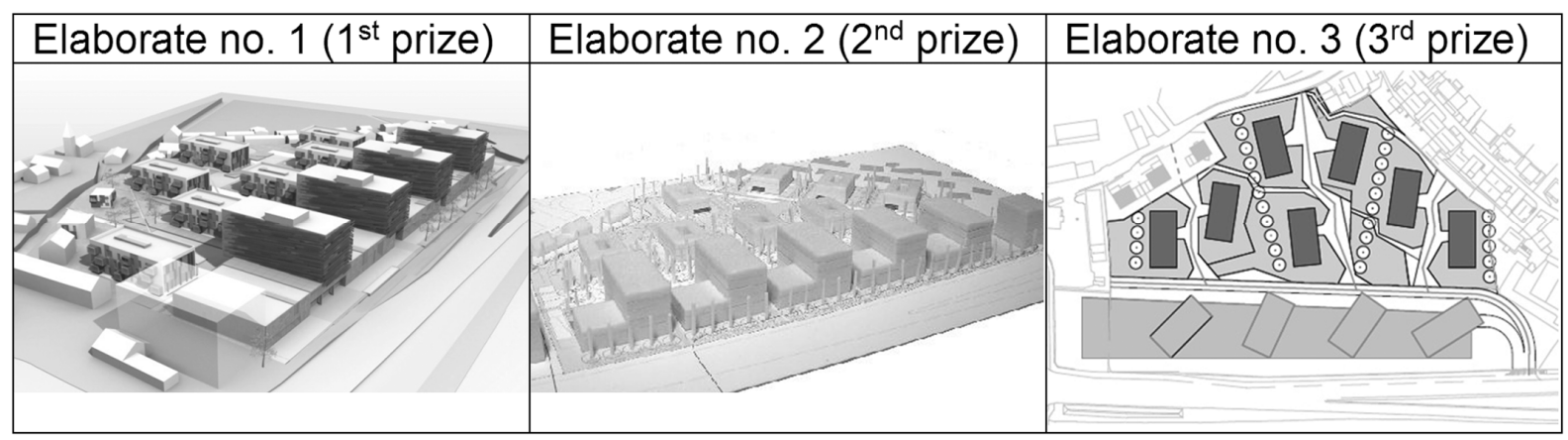

Figure 18. Conceptual design of all three prize-winning competition solutions (At the front: commercial buildings, at the back: residential buildings)

In the case of competition entry No. 1 (Figure 19), the small towers are constructed just above the dilatation joints of the lower (commercial) part of building. This kind of design could result in concentrations of stresses in the connections between the towers and the lower, commercial part of the building, since the upper structures would oscillate at quite different frequencies to the lower structure. The other thing to be noticed is that the structural cores of the towers are located very eccentrically, which will cause torsion in plan. Otherwise, the structure of competition entry No. 1 is simple, with clear continuity in elevation, and has an adequate arrangement of the most important structural elements, with smaller, manageable cantilevers.

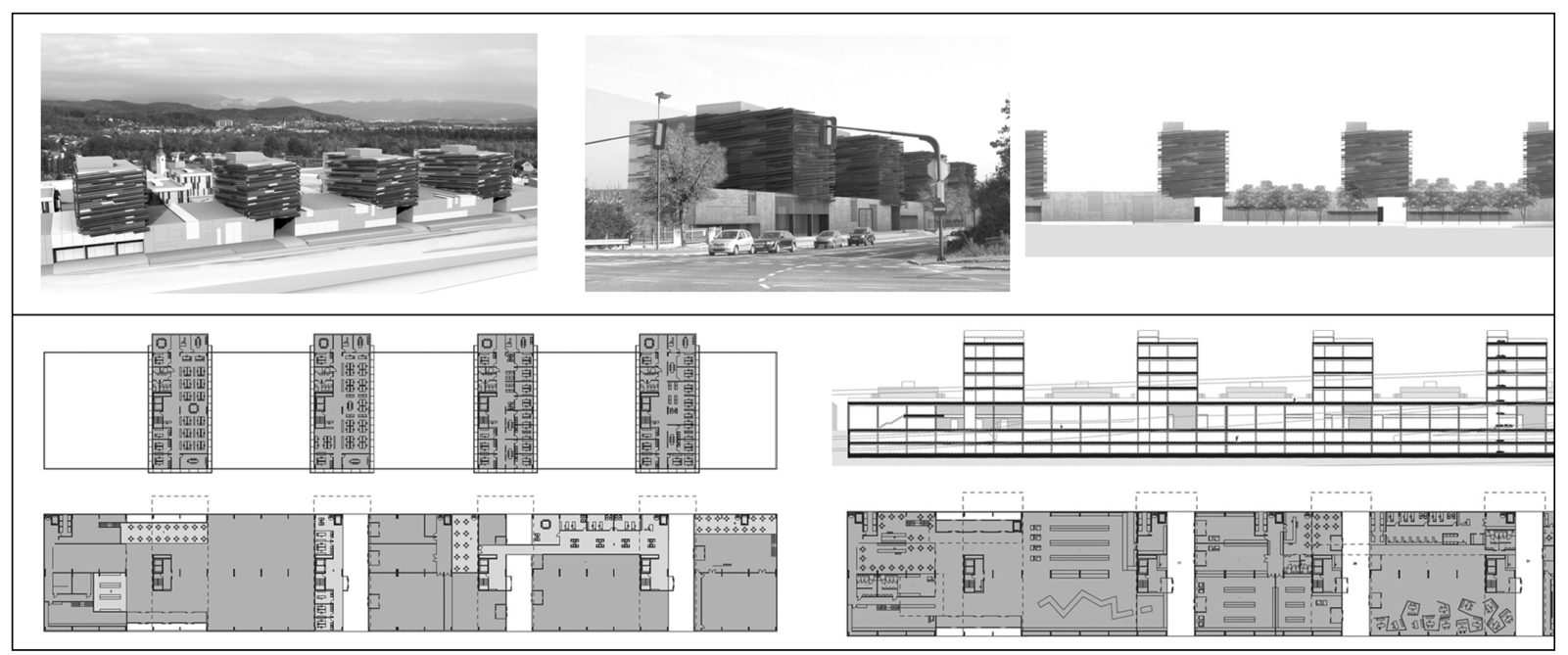

Figure 19. Concept and characteristics of competition entry No. 1

The architectural response follows the tectonic load paths of the massive lower base, supporting apparently light glass volumes. The symbolism of earthquake resistance is suitable in spite of the dynamic diagonal concept of the brisoleils. However, it is noticeable that the small towers are located at the most vulnerable positions of the lower part of the building, and also that the upper and lower parts are not well connected together. The thin bearing walls, with only a relatively weak connection as a support, do not correctly respond to the volume of the upper towers. 
The concept proposed by competition entry No. 2 (Figure 20) consists of five equal compact buildings, which are ' $L$ ' shaped both in plan and in elevation, resulting in a potentially very inconvenient configuration especially in elevation. It is not the best solution to place a single core in the middle of a floor plan, without any structural walls (just reinforced concrete frames) on the perimeter of the buildings. Such structures might have a reduced torsional resistance. In the case that the higher part is structurally separated from the lower part by dilatations, the problem of increased torsion in plan occurs. In case of the non-divided part of the building, the structural core placed nearby the re-entrant corner is a good solution, but the problem of irregularity in elevation remains.

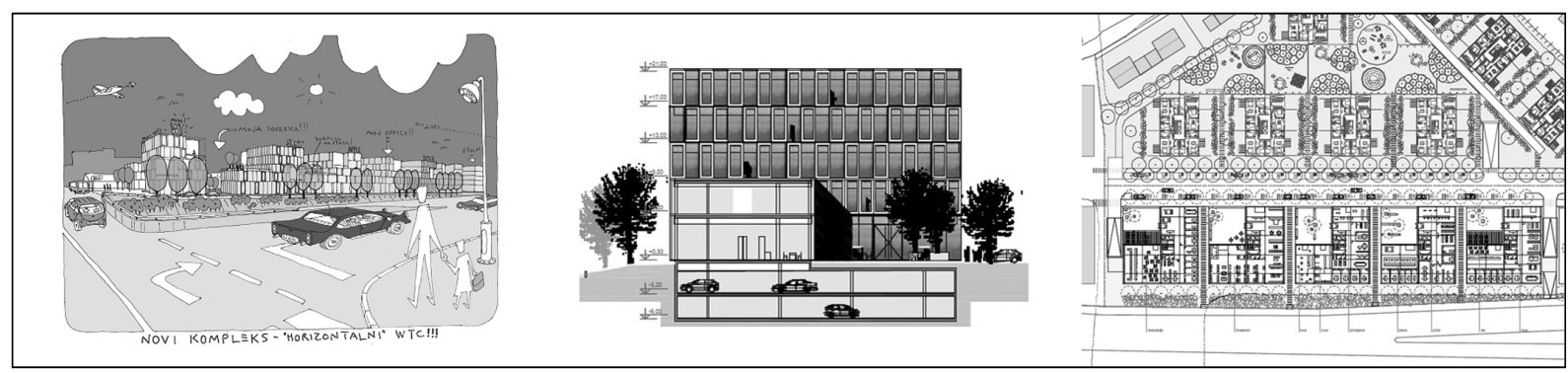

Figure 20. Concept and characteristics of competition entry No. 2

Competition entry No. 3 (Figure 21) expresses many inconsistencies and is even partly in opposition to the logic of earthquake-resistant design. Similarly, as in the case of the first competition entry, this solution presents a long, two-storeyed commercial lamella, which supports the four four-storey business volumes. The upper structures do not coincide with layout of the columns in the lower part of the structure. The main structural cores, although with continuity in elevation, are placed at the edges of the upper volumes, and even outside of them. Because of the rotation of these volumes, the main structural directions do not coincide with the main load-bearing directions of the cores. Such a structural design inevitably leads to severe torsion in plan, and to a concentration of stresses in the perimeter columns and in the beams which support the columns of the upper structure. There are also several wide cantilevered elements, which are inadequately connected to the rest of the structure.

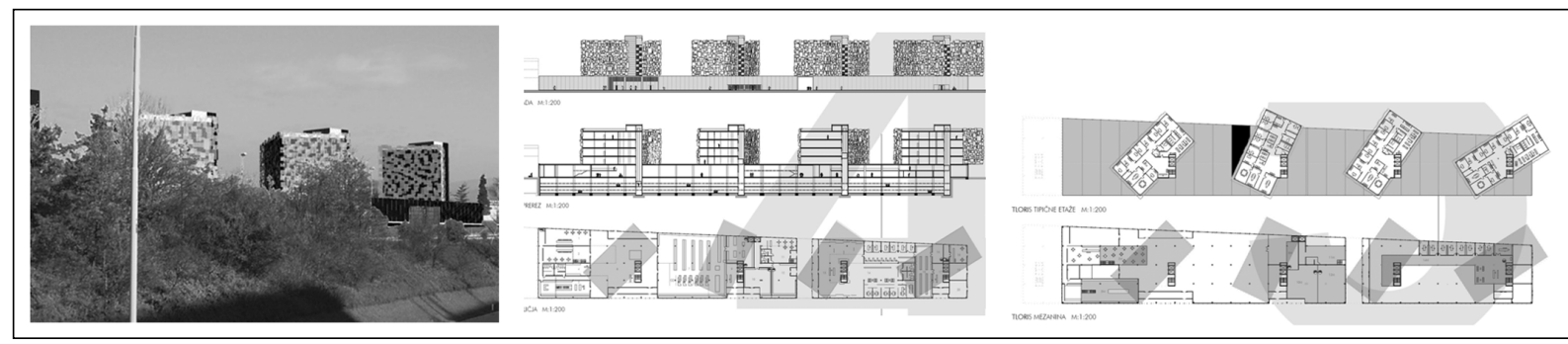

Figure 21. Concept and characteristics of competition entry No. 3

\subsection{General Observations}

In general it can be seen that the second competition entry (No. 2) has a higher level of anti-earthquake logic in its design concept, taking into account the mentioned difficulties which will be solved by detailing, dilatations and/or the reinforcement of the perimeter structure, which will move the centre of rigidity closer to the centre of masses. Competition entry No. 1 has a well-based and regular earthquake-resistant structure, although it also has the problem of the eccentricity of its core. Insufficient seismic symbolism and tectonically less logical load paths are demonstrated by placing the upper structures (i.e. towers) at critical locations above the lower part. This may challenge the sense of solidly supported mass.

The third building (competition entry No. 3), with a low score and inadequate structural principles, appears to ignore seismic reality, and to oppose the usual standards of earthquake engineering. On the other hand architectural perception works better with the tectonics of compact volumes supported by a strong low base, which could evoke trust. This impression is changed completely by a more detailed overview of the glazed structure of the lower part, with a distinctive discontinuity in elevation. 


\subsection{Evaluation, Interactive Tables and the Results in Radial Form}

The interactive tables (Figures 22-24) show that the external parameters reach the same values for all three buildings. This building is of medium importance, with larger public areas; and is located near a main city road not far from the city centre. Thus, the general architectural parameters and the symbolic value of the building are weighted slightly higher than the other parameters. The importance, public areas, and functionality of the commercial building results also in a higher weighting of the first three and the $6^{\text {th }}$ structural parameter.

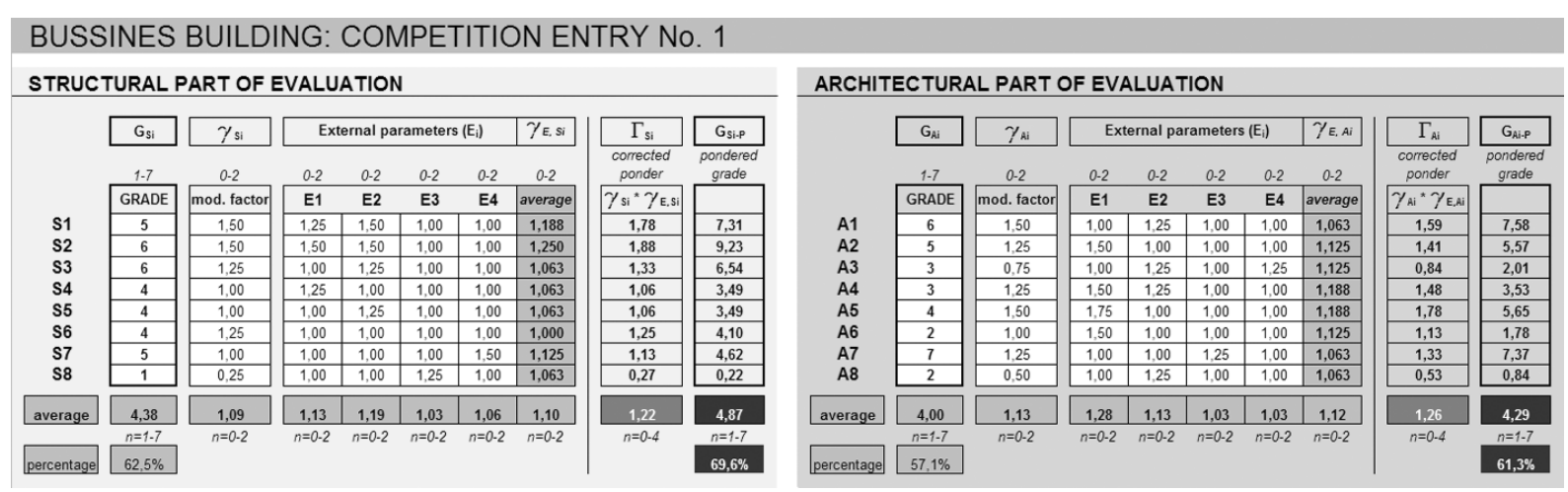

Figure 22. Interactive table corresponding to the evaluation of competition entry No. 1

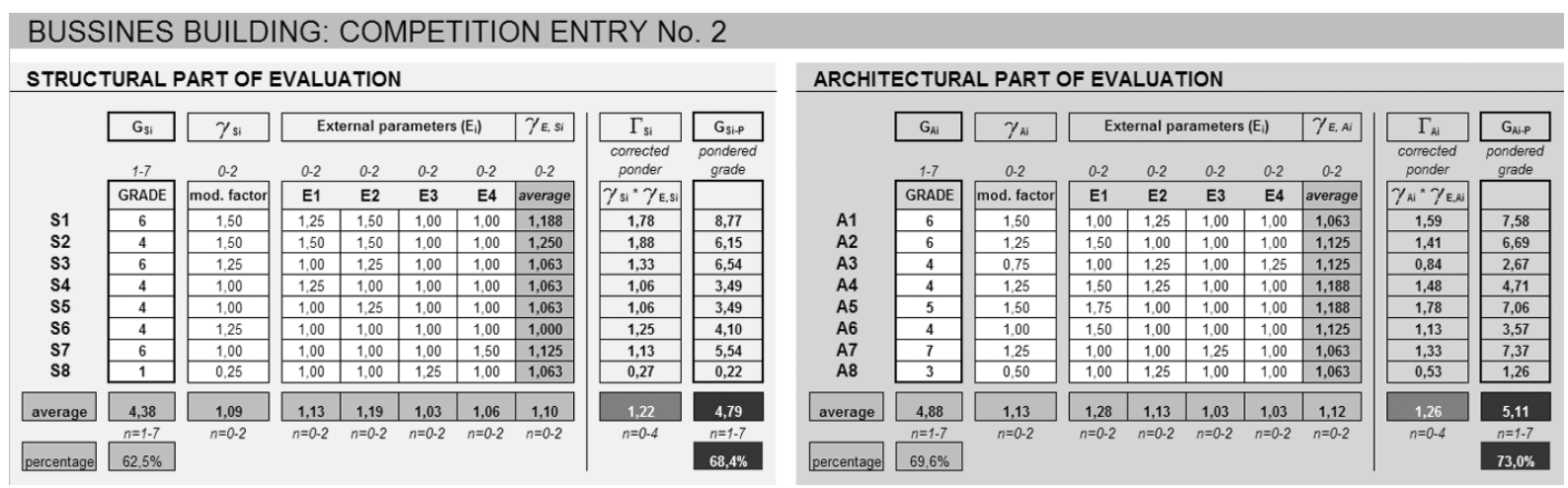

Figure 23. Interactive table corresponding to the evaluation of competition entry No. 2

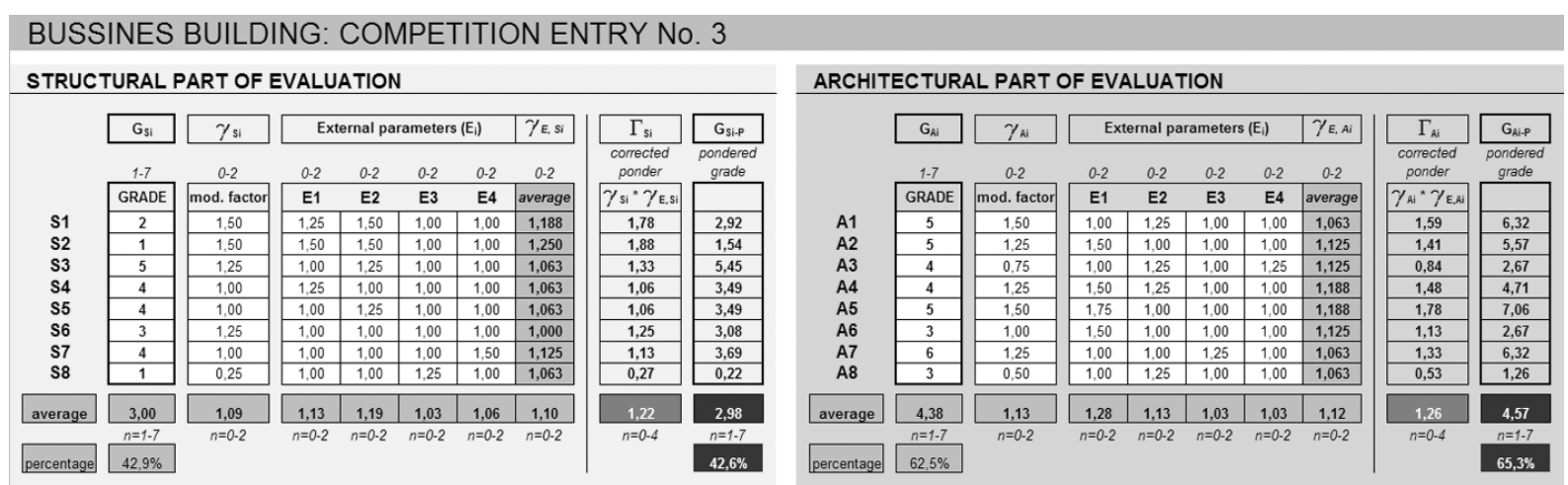

Figure 24. Interactive table corresponding to the evaluation of competition entry No. 3

The results in radial form (Figure 25) show larger differences between the structural and architectural parts of the evaluation of competition entry No. 3. It is clear that the main concept of this architectural composition did not (at this stage) take earthquake reality into account. Execution of this solution would demand major structural changes, which would have an effect on the architectural concept. Without these changes such a design could be typical for anti-earthquake architecture, with a "zero-level". Competition entry No. 1 reaches a convenient level of earthquake architecture mostly by its regular structural scheme and tectonic concept, which could be easily 
improved by considering the results of this evaluation. The most harmonious architectural and structural parts of the evaluation are achieved in the case of competition entry No. 2, which reaches an even higher score than entry No. 1, although there is nothing to express earthquake resistance especially. It uses the natural logic of simple, compact volumes, expressed in the clear tectonic configuration of the building(s).

COMPETITION ENTRY No. 1

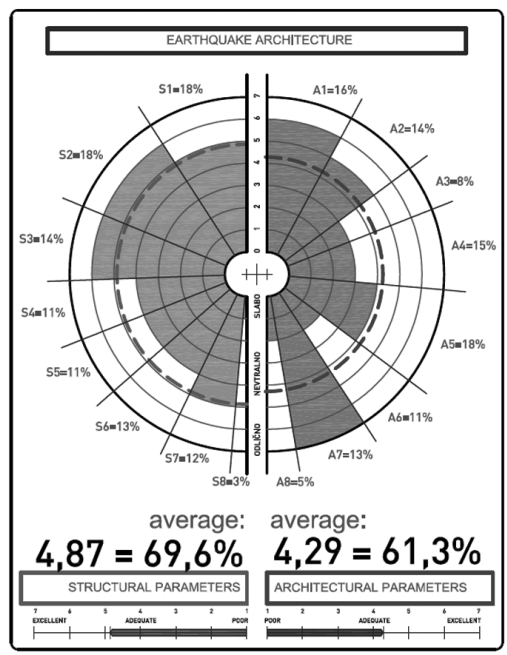

COMPETITION ENTRY No. 2

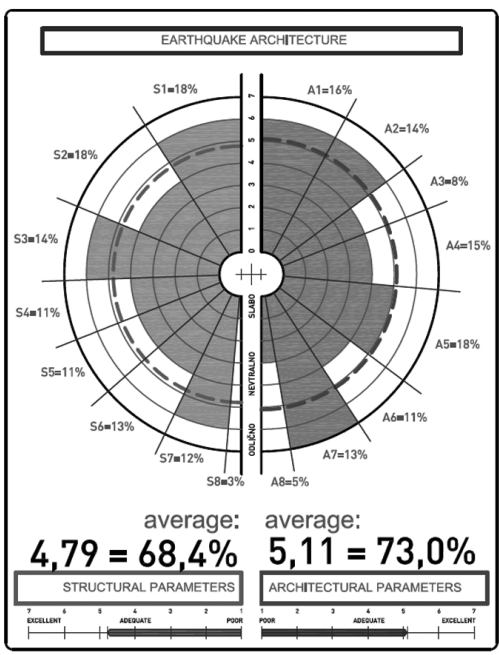

COMPETITION ENTRY No. 3

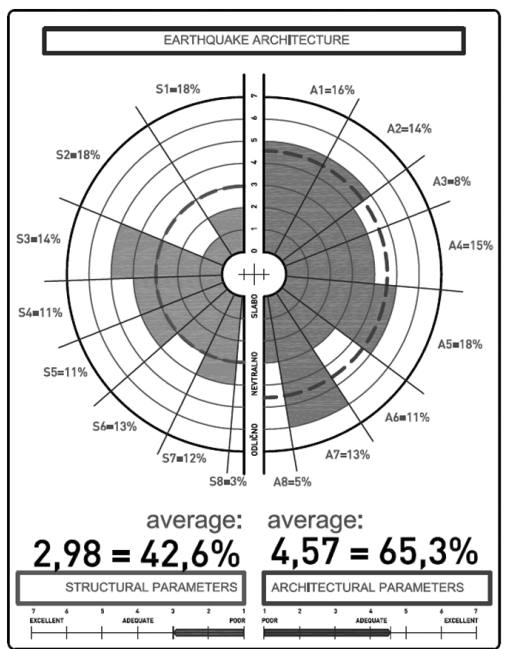

Figure 25. Graphical representation of the method for the evaluation and identification of earthquake architecture as a result of the evaluation of all three comparable contest solutions. The architectural (A1-A8) and structural (S1-S8) parameters, and their average values, show the level of architectural and structural response to an earthquake of a certain building

\section{Conclusions}

Conclusions could be summarized in few main points as follows:

- $\quad$ This paper introduces an alternative design approach in earthquake prone areas arising from the principles of so called "earthquake architecture".

- $\quad$ Earthquake architecture, which is defined as architecture within the context of seismic resistance, represents a special approach to architectural design, in which the main source of inspiration comes from earthquake engineering, and where specific local tectonic activity can become a generator for architectural design.

- In addition to that a new method for the evaluation of the architectural and structural earthquake logic of new or existing buildings is presented. Using the proposed method, it is possible to determine the adequacy of structural concepts and architectural expression of earthquake resistant design and to classify (earthquake) architecture at several intensity levels in the sense of seismic resistance. A reliable evaluation of the proposed evaluation criteria, however, requires a certain amount of architectural and structural engineering expertise, and should therefore be performed by an expert.

- The method presents an instrument which could, potentially, be widely used in order to reveal the interaction between architecture and earthquake-resistant construction. It is intended for research purposes, for comparative studies among buildings or groups of buildings.

- The method is also intended to be used as additional tool for the assessment of the results of architectural competitions, which often lack the judgement on seismic resistance level of particular architectural solution.

- $\quad$ Proposed method can be looked at also in more general sense, as it might be used - with appropriate adjustments - in any evaluation of artistic value in combination with certain technical requirements and guidelines.

- It is believed that the method also has educational value, as it could contribute to the elimination of problems related to the lack of knowledge required for good architectural design in seismic areas. 
- It can also be concluded that earthquake architecture represents a particular kind of unused architecture potential, which presents an important source for a stronger architectural identity arising from local tectonic activities in earthquake-prone regions.

\section{References}

Alexander, C. (2002). The Nature of order - Book 1: The Phenomenon of Life. The Center for Environmental Structure. Berkeley. cop.

Arnold, C. (1996). Architectural aspects of Seismic resistant Design. Proceedings of the $11^{\text {th }}$ World Conference on Earthquake Engineering.

Arnold, C. (2001). Architectural Considerations (chapter 6), The Seismic Design Handbook(2ed.). Kluver Academic Publishers, Norwell, MA.

Charleson, A. W., \& Taylor, M. (2000). Towards an Earthquake Architecture, Proceedings $12^{\text {th }}$ World Conference on Earthquake Engineering January 2000. NZ National Society for Earthquake Engineering, Paper 0858, p. 8 .

Charleson, A. W., \& Taylor, M. (2004). Earthquake architecture explorations. Paper 596, 13 ${ }^{\text {th }}$ World Conference on Earthquake Engineering, Vancouver.

Ciorra, P. (1995). Peter Eisenman. Bauten und projekte. Deutsche Verlags-Anstalt GmbH, Stuttgart.

FEMA, No. 178. (1992). NEHRP Handbook for the Seismic Evaluation of Existing Buildings. FEMA (Federal Emergency Management Agency). Washington, D. C.: Building seismic safety Council.

FEMA, No. 454. (2006) Designing for Earthquakes, A manual for architects. FEMA (Federal Emergency Management Agency). Washington, D. C.: Building seismic safety Council.

Fernandez-Galiano, L. (2000). Earthquake and therapy. In: Lotus International, no. 104, Elmond SpA, Milano.

Forster, K. W. (1999). Why Are Some Buildings More Interesting Than Others? Harward Design Magazine. Winter/Spring 1999, No. 7. Harward University Graduate school of Design. Cambridge, MA. http://www.gsd.harvard.edu/research/publications/hdm/

Frampton, K. (1982). Towards a Critical Regionalism: Six Points for an Architecture of Resistance in the Anti-Aestetic: Essays on Postmodern culture. Bay Press, Washington.

Frampton, K. (1985). (revised and enlarged edition): Modern Architecture: A Critical History. Thames and Hudson Ltd. London.

Garcia, B. (2000). Earthquake Architecture, New construction techniques for earthquake disaster prevention. Loft Publications, Barcelona.

Giedion, S. (1997). Space, Time and Architecture: The growth of a new tradition (5th ed.). Revised and enlarged, 13th printing. Cambridge: Harvard University Press.

Kilar, V. (2000). Evaluation of earthquake vulnerability of existing building structures - Proposal. Research report, University of Ljubljana, Faculty of architecture.

Kilar, V. (2004). Ocena potresne ogroženosti stanovanjskih stavb v Sloveniji = Evaluation of earthquake vulnerability of residential buildings in Slovenia. AR, Arhit. razisk., No. 1. University of Ljubljana, Faculty of architecture.

Medway, P., \& Clark, B. (2003). Imagining the building: architectural design as semiotic construction. Design Studies, 24(3).

Mezzi, M., Parducci, A., \& Verducci, P. (2004). Architectural and Structural Configurations of Buildings with Innovative Aseismic Systems, Proceedings of the 13. WCEE.

Reitherman, R. (1985). Earthquake Engineering and Earthquake Architecture. Part of the AIA "Workshop for Architects and Related Building Professionals" on Designing for Earthquakes in the Western Mountain States. Retrieved from http://www.curee.org/architecture/

Saunders, W. S. (1999). From Taste to Judgement. Multiple criteria in the evaluation of architecture. Harvard Design Magazine, Winter/Spring 1999, No. 7. Harvard University Graduate School of Design, Cambridge, MA. Retrieved from http://www.gsd.harvard.edu/research/publications/hdm/ 
Slak, T., \& Kilar, V. (2007). Earthquake architecture as an expression of a stronger architectural identity in seismic areas. In: Brebbia, Carlos Alberto (ed.). Earthquake resistant engineering structures VI. Ashurst, Southampton; Boston: WIT Press. http://dx.doi.org/10.2495/ERES070081

Slak, T., \& Kilar, V. (2008a). Simplified ranking system for recognition and evaluation of earthquake architecture. In: 14th World Conference on Earthquake Engineering. Conference proceedings: Beijing, China. Beijing: Chinese Association of Earthquake Engineering: International Association for Earthquake Engineering.

Slak, T., \& Kilar, V. (2008b). Assessment of Earthquake Architecture as a Link between Architecture and Earthquake Engineering. Prostor (Zagreb), No. 2(36), pp. 155-167.

Slak, T., \& Kilar, V. (2011). Development of Earthquake Resistant Architecture from Intuitive to Engineering Approach. Prostor (Zagreb), No. 1(41), pp. 252-263.

Taranath, B. S. (2011). Structural Analysis and Design of Tall Buildings. Steel and Composite Constructions. CRC Press, Taylor \& Francis Group.

Tomaževič, M. (1996). Assessment of seismic resistance and criteria for seismic rehabilitation of historic urban masonry buildings. Acta polytech., 36(2).

Tomaževič, M. (2001). Seismic assessment and retrofit of masonry structures. In: Badoux, Marc (ed.), Lateltin, Olivier (ed.), Tissières, Pascal (ed.). Seismic assessment and upgrading of existing structures: proceedings. [Zürich]: EAEE, SGEB.

Xu, R. P., Xing, S. J., \& Guan, B. J. (2012). Discuss on the Unification of Architecture Innovation and Structure Form. Advanced Materials Research, 450-451, 952-955. 